\title{
Characterization of some local varieties of fig tree (Ficus carica L.) in Oued Laou region of
} Morocco

\author{
El Oualkadi A*, Hajjaj B*
}

*INRA- Regional Agricultural Research Center of Tangier, Morocco

Corresponding author. E-mail: ai.oualkadi@gmail.com

\begin{abstract}
A Prospection was conducted at the Oued laou region of Morocco in order to evaluate the existing genetic resources and collect the local fig cultivars of the zone. As a result, a total of 121 different accessions were collected and studied for preliminary variety identification, which was confirmed on the basis of biometric observations. Several synonymies and homonymies were detected. A total of 13 different cultivars were identified. Comparison of the ecotype shows the high significatif difference. Conservation of the local cultivars is highly recommended.
\end{abstract}

Keywords - fig tree, genetic resources, biometric analysis, Oued Laou, Morocco.

\section{INTRODUCTION}

Common fig (Ficus carica L.) is an fruit crop cultivated in Mediterranean countries since antiquity. Common fig is considered, together with grape (Vitis vinifera L.) and olive (Olea europaea L.), classical fruit trees associated with the beginning of horticulture in the Mediterranean Basin [1], and consequently it is one of the earliest domesticated fruit tree species [2] ; [3]; [4]. In fact, recent studies [5] indicate that common fig is probably the first domesticated crop of the Neolithic revolution. This fruit crop is widespread in the Mediterranean basin countries since it is well adapted to either different soils or climates [6]. Despite its socioeconomic and historical importance, fig is considered a minor fruit species in Morocco. The regions in which the fig tree assumes economic importance are Taounate (22230 ha), Chefchaouen (7050 ha), Al Hoceima (5000 ha), Ouazzane (3150 ha), Tetouan (2000 ha) [7]. In Morocco, the production of fresh figs in 2018 growing season for fresh consumption was approximately 57000 tons with a total area of 46000 hectares (ha) of fig plantations in Morocco [7]. Particularly, in rural area, fig production assumes economic importance mainly in Ouad Laou area. Surveys done in different regions of Morocco contributed to identify and describe numerous cultivars [8]; [9]; [10]; [11]. In the present work, a prospection has been carried out during the period from 2015 to 2016 in the Northwestern (Oued Laou region) of the Morocco, in order to collect unknown or endangered varieties and avoid their extinction. The study focuses in old plantations by contributing to identify and collect minor or neglected varieties that in many cases had local names, and were unknown in others. Pomological parameters description has been carried out in order to identify the studied varieties.

\section{MATERIAL AND METHODS}

Prospection and sampling have been carried out at different localities in Oued Laou region in Northwestern of morocco (fig. 1). In total 121 accessions were gathered. In many cases, either isolated plants or plants located at old fig plantations areas were sampled (Table 1).

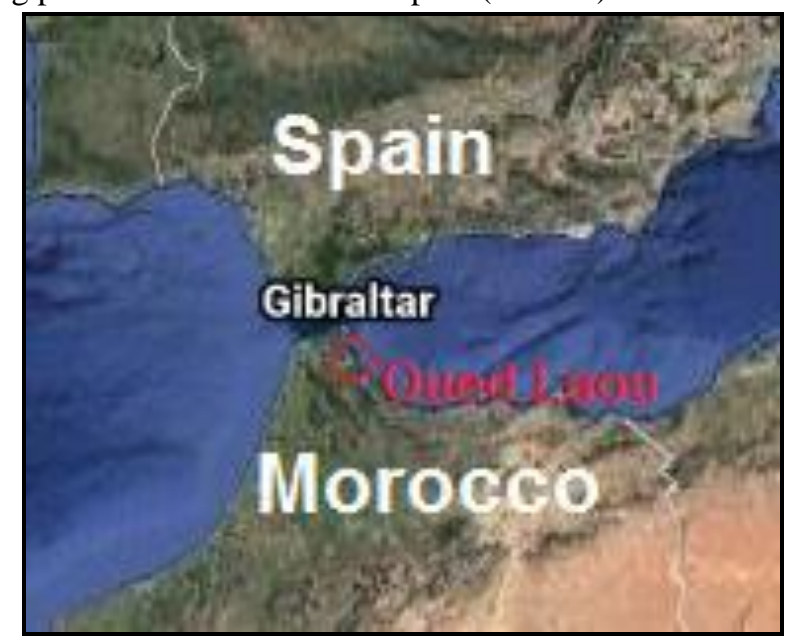

Fig. 1. Collection sites. 
Table 1: Key data for location of prospecting sites

\begin{tabular}{|c|c|c|c|c|c|}
\hline Number of ecotype & Douar & Caîdat & Locatlity & Altitude & Geographic coordinate \\
\hline \multirow{2}{*}{25} & \multirow{2}{*}{ Riffiyine } & \multirow{2}{*}{ Oued laou } & \multirow{2}{*}{ Sidi kassim } & \multirow{2}{*}{$25 \mathrm{~m}$} & $35^{\circ} \mathrm{N}-31,12^{\prime}$ \\
\hline & & & & & $0,5^{\circ} \mathrm{W} 13,949^{\prime}$ \\
\hline \multirow[t]{2}{*}{24} & \multirow[t]{2}{*}{ Tamernoute } & \multirow[t]{2}{*}{ Amsa } & \multirow[t]{2}{*}{ Sidi kassim } & \multirow[t]{2}{*}{$33 m$} & $35^{\circ} \mathrm{N}-31,026^{\prime}$ \\
\hline & & & & & $0,05^{\circ} \mathrm{W}-10,832^{\prime}$ \\
\hline 24 & Awchtam & Amsa & Sidi kassim & $35 \mathrm{~m}$ & $\begin{array}{c}35^{\circ} \mathrm{N}-30,293^{\prime} \\
0,5^{\circ} \mathrm{W}-10,093^{\prime}\end{array}$ \\
\hline 24 & Tamernoute & Khandk lghrik & Kaâ asrass & $71 \mathrm{~m}$ & $\begin{array}{c}35^{\circ} \mathrm{N}-24,300^{\prime} \\
0,05^{\circ} \mathrm{W}-03,200^{\prime}\end{array}$ \\
\hline 24 & Tarzoute & Arbaa beni hassan & Talamboute & $298 m$ & $\begin{array}{l}35^{\circ} \mathrm{N}-15,9871^{\prime} \\
0,5^{\circ} \mathrm{W}-13,822^{\prime}\end{array}$ \\
\hline
\end{tabular}

\section{Plant material}

Fig fruits from eight cultivars (Ferzaouia, Baghi, Gaouzi, Tabli, Baghi assal, Harchi, Roudane, Kharaza, Meltoufa, Harchi lkhal, harchi labyad, Hazouta and Tahadakte) were harvested from the five respective areas during cropping seasons 2015 and 2016. Cultivars were selected for their large distribution and their commercial value in the five regions. Samples of 121 homogenous fruits (three replicates of 10 fruits each) were chosen for each ecotype. Fruits were selected ripe and free from diseases.

\section{Pomological characters}

\section{Biometric Approach}

To examine the characteristics of the fruit for each ecotype, it was considered useful to approach a biometric study of the fruit based on the evaluation of the weight, caliber, dimensions and ostiole of the fruit. For each ecotype, a sample of twenty four fruits was randomly collected from different branches of the tree. Fruit weight was measured using a laboratory precision balance. Dimensions of the fruits such length, width, height and ostiole width were measured using a caliper (Figure 2). The descriptors used were adapted list drawn up by European program GEN LMBO 029 [12].

General appearance of the fruit:

The general appearance of the fruit corresponds to its external form. In this aspect, we were interested in the shape and size of the fruit.

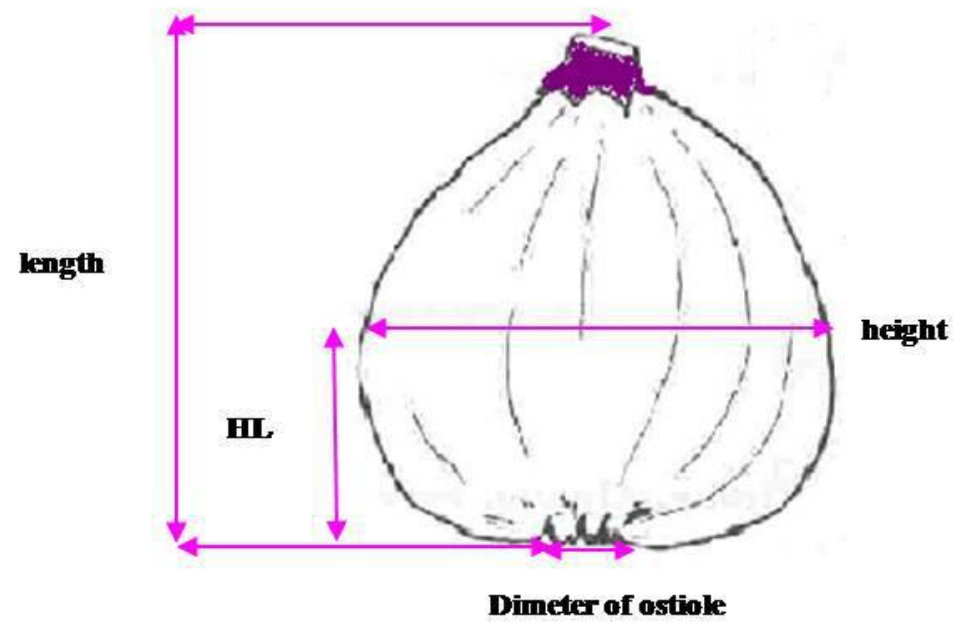

Fig.2: Representative diagram of measurements made on fig fruit

\section{Fruit Shape}

The fruits are of variable shape within the same tree and during the same season [13]. To avoid this hazard, we often rely on the presence or absence of neck. Other authors rely on three dimensions of the fruit to differentiate the varieties: the length $\mathrm{C}$, the diameter $\mathrm{D}$, and the distance A separating the base from the center of the circle of diameter $\mathrm{D}$. The study of the shape of the fruit is important because it is related to the treatment that is applied to it. This is how the flattened shape with a short neck is ideal for canning. Other forms require certain precautions during transport; and others may facilitate the marketing of fresh fruits.

Statistical analysis

Comparison between the ecotype was made by statistical analysis of collected data. Statistical analyzes are performed 
with SPSS software version 21. Ghraphs was made by Excel version 2013.

\section{RESULT AND DISCUSSION}

Many of the sampled accessions were collected either as unidentified or with local names. As result of the biometric approach the prospected plant material was characterized. 121 accessions were identified in owed law region. The average weight of the varieties studied (Fig 3) varied from $23.1 \mathrm{~g}$ to $57.92 \mathrm{~g}$. The Tahadakte variety shows the highest weight while the Hafzaouia variety shows the lowest weight. The analysis of variance showed 10 homogeneous groups from the weight fruit (Table 2). The variety Hazouta, Harchi lkhal, Rhoudane and Gaouzi are significantly not different for the parmeter weight of fruit. The varieties Ferzaouia and Tabli are significantly not different. The varieties Kharaza, Baghi, Tahadakte, Harchi lbayd, Meltoufa, Harchi and Baghi assal form each one a group significanlty diffrent from pthers for wight fruit (Table 2).

The average length of the fruit varied between $3.9 \mathrm{~cm}$ and $5.25 \mathrm{~cm}$ (Fig. 4), the variety Hazouta showed the greatest value of the length of the fruit whereas the variety Tabli showed the lowest value of the length of the fruit. Gaouizi, Rhoudane, kharaza, Meltoufa, Tahadakte and Hazouta , are not significantly different. Ferzaouia, Baghi assal are not significantly. The variety Tabli, Harchi, Harchi Labyad, Baghi, Harchi lkhal formed each one group significantly different from each other and from others groups (Table 2).

The width of the fruit varied between $3.43 \mathrm{~cm}$ and $5.11 \mathrm{~cm}$ (Fig 5), the Rhoudane variety shows the weaker the value of width fruit while the variety Ferzaouia shows the greatest value of the width of the fruit (Fgi.5). The variety Gaouizi, Harchi, Harchi labayd, Tahadakte and Hazouta groued in one group and they are significantly not different from the width of fruit. Also the variety Kharaza and Baghi are significantly not different (Table 2).

The value of HL varied between $2.53 \mathrm{~cm}$ and $1.83 \mathrm{~cm}$ (Fig.6), the variety Ferzaouia shows the greatest value (2.53 $\mathrm{cm}$ ) while the variety Tahadakte shows the lowest value 1.83 $\mathrm{cm}$. The variety Gaouizi, Baghi assal, Harchi and Rhoudane are not significantly different, also the variety Ferzaouia, Tabli and Meltoufa are not significantly different. The variety Harchi Labyad and Baghi are not significantly different from the parmeter HL fruit (Table 2).

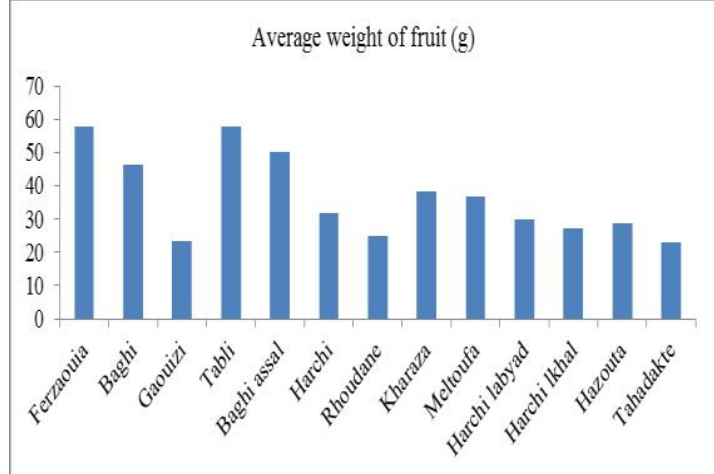

Fig 3 : Average weight of fruit

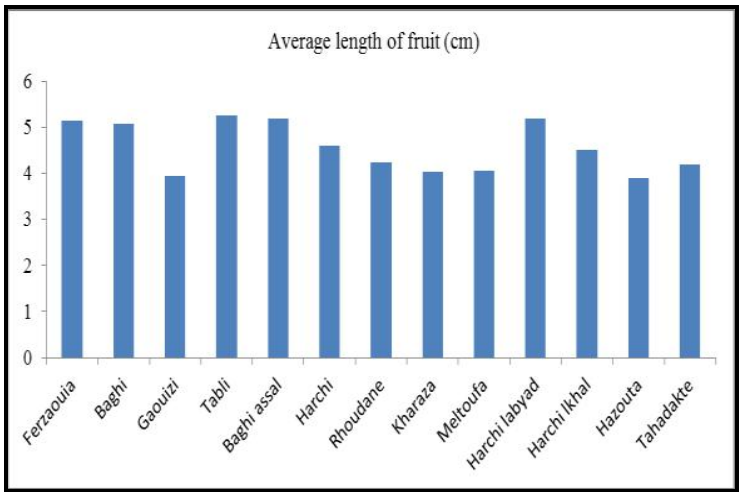

Fig 4: Average length of fruit $(\mathrm{cm})$

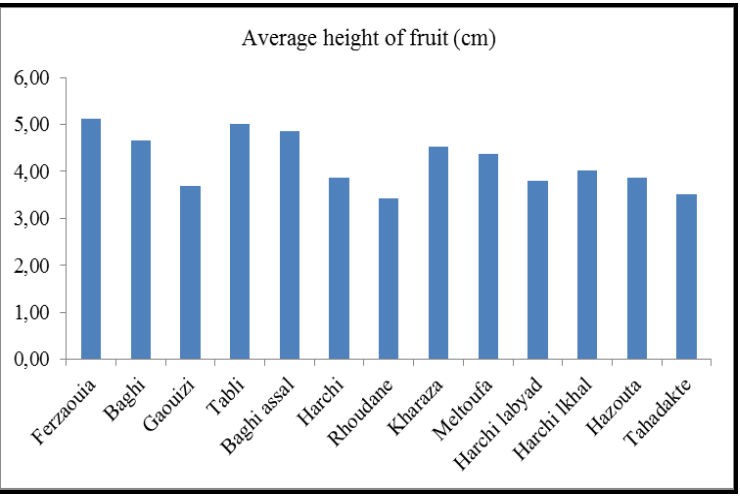

Fig 5 : Average height of fruit $(\mathrm{cm})$

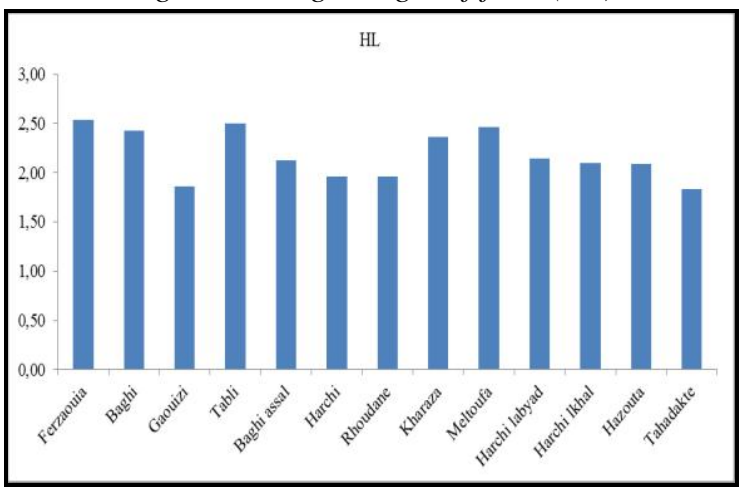

Fig 6: HL of fruit 

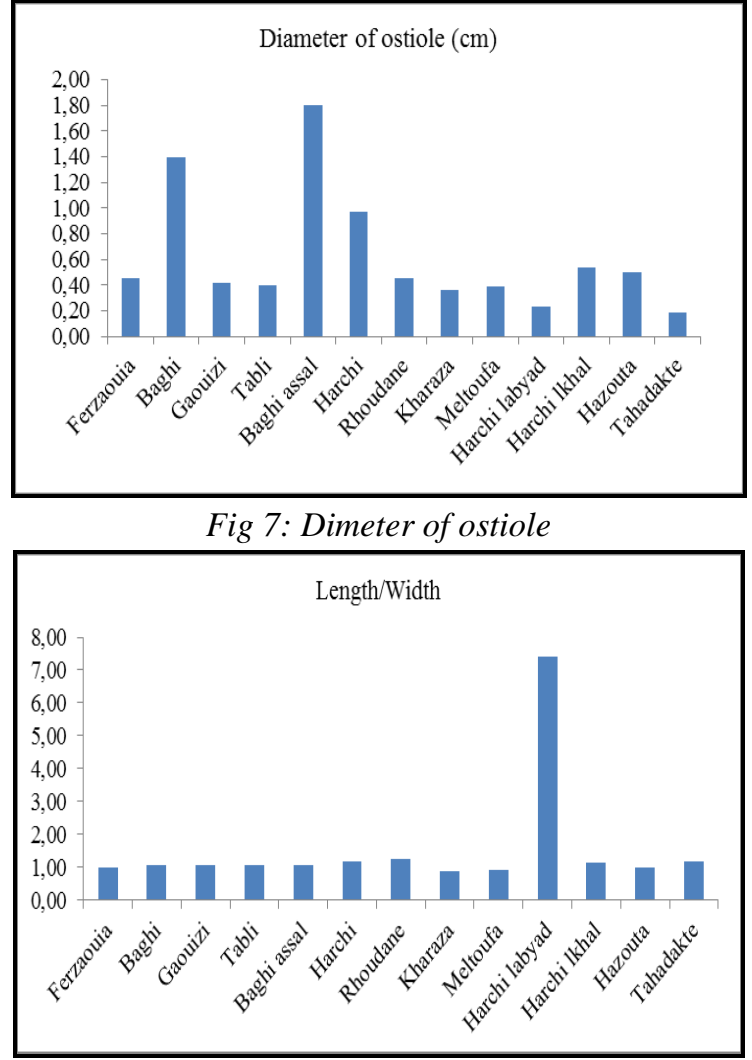

Fig 8: Length / width of fruit

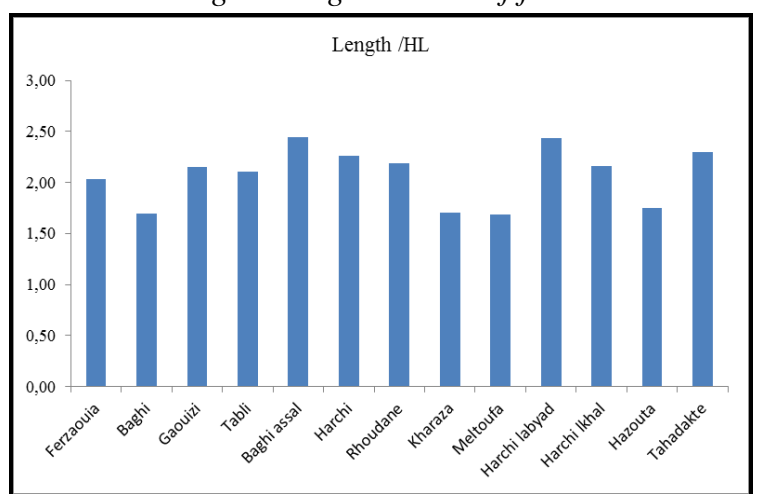

Fig 9: Length / HL of fruit
The diameter of the ostiole varied between $0.19 \mathrm{~cm}$ and 1.80 $\mathrm{cm}$ (Fig.7) the variety Tahadakte shows the smallest value of the diameter of the ostiole whereas the variety Baghi Assal shows the greatest value of the diameter of the ostiole. The analysis of variance show that the variety Ferzaouia, Baghi assal, Harchi, Rhoudane, Baghi, Harchi lkhal and Hazouta are not significantly different. The variety Gaouizi and Tabli are not significantly different. Also the variety Kharaza and Meltoufa are not significantly different from diameter of ostiole (Table 2)

The length/ Width ratio of the fruit varies between 0.89 and 7.42 (Fig. 8), the greatest value of the length / width ratio of the fruit was observed in the Harchi labyad variety, while the lowest value was observed in the variety Kharaza. The analysis of variance shows that the variety Gaouizi, Baghi assal and Harchi lkhal are not significantly different. Also the variety Ferzaouia and Hazouta are not significantly different (Table 2).

The length / HL of the fruit varied between 1.68 and 2.45 (Fig. 9), it is found that the variety Meltoufa showed the lowest value of the ratio length / HL while the variety Baghi Assal showed the most great value. Table 2 show that the variety Harchi, Rhoudane, Baghi and Tahadakte are not significantly different.

In these results, we find that the variety Ferzaouia showed the greatest value of the weight of the fruit, HL and the width of the fruit. And the Baghi assal variety showed the greatest value of the ostiole diameter and the length / HL when the Tahadakte variety showed the lowest value of fruit weight and ostiole diameter.

Table 2: Biometric characteristics of fig cultivars harvested from the region

\begin{tabular}{|c|c|c|c|c|c|c|c|}
\hline Variety & Weight $(\mathrm{g})$ & length $(\mathrm{cm})$ & width $(\mathrm{cm})$ & $\mathrm{HI}(\mathrm{cm})$ & Diameter of ostiole $(\mathrm{cm})$ & Length/Width & Length / HL \\
\hline Ferzaouia & $57,92 f$ & $5,13 b c d$ & $5,11 f$ & $2,53 d$ & $0,46 c$ & $1,02 b c d$ & $2,03 b c$ \\
\hline Gaouizi & $23,47 a b$ & $3,96 a$ & $3,69 a b$ & $1,86 a b$ & $0,42 b c$ & $1,08 \mathrm{def}$ & 2,15 cde \\
\hline Tabli & $57,78 f$ & $5,26 d$ & 5,00 ef & $2,50 d$ & $0,40 b c$ & 1,06 cde & 2,11 bcde \\
\hline Baghi assal & 50,28 ef & $5,14 b c d$ & 4,76 def & $2,06 a b$ & $0,56 c$ & 1,08 def & $2,51 e$ \\
\hline Harchi & $31,80 \mathrm{bcd}$ & $4,59 a b c$ & $3,87 a b$ & $1,96 a b$ & $0,52 c$ & 1,18 efg & $2,26 \mathrm{de}$ \\
\hline Rhoudane & $25,08 \mathrm{ab}$ & $4,24 a$ & $3,43 a$ & $1,96 a b$ & $0,46 c$ & $1,24 g$ & 2,19 de \\
\hline Kharaza & $38,10 d$ & $4,03 a$ & $4,51 d e$ & $2,36 \mathrm{ce}$ & $0,36 a b c$ & $0,89 b$ & $1,71 b$ \\
\hline Meltoufa & $36,86 \mathrm{~cd}$ & $4,05 a$ & $4,36 c d$ & $2,46 d$ & $0,39 a b c$ & $0,93 b c$ & $1,68 b$ \\
\hline Harchi labyad & $29,85 a b c$ & $5,19 c d$ & $3,81 a b$ & $2,14 b d$ & $0,23 a b$ & $0,00 a$ & $0,00 a$ \\
\hline Baghi & $47,06 e$ & $5,62 d$ & $4,57 \mathrm{de}$ & $2,16 b d$ & $0,54 c$ & $1,23 f g$ & $2,39 \mathrm{de}$ \\
\hline Harchi lkhal & $27,20 \mathrm{ab}$ & $4,52 a b$ & $4,02 b c$ & $2,10 \mathrm{a} b c$ & $0,48 c$ & 1,14 def & 2,16 cde \\
\hline Tahadakte & $23,10 a$ & $4,19 a$ & $3,52 a b$ & $1,83 a$ & $0,19 a$ & 1,19 efg & $2,30 \mathrm{de}$ \\
\hline Hazouta & $28,63 \mathrm{ab}$ & $3,90 a$ & $3,87 a b$ & $2,08 a b c$ & $0,50 c$ & $1,00 \mathrm{bcd}$ & $1,75 b c$ \\
\hline
\end{tabular}




\begin{tabular}{llllllll}
\hline$P \alpha=0.05$ & 0 & 0 & 0 & 0 & 0 & 0 & 0 \\
\hline
\end{tabular}

Significant differences within the same column and means followed by the same letter do not differ at P $\alpha \leq 0.05$ according to Duncan test.

\section{CONCLUSIONS}

The present study highlights the necessity to identify the cultivars in the region of Oued Laou in Northwestern Morocco. The plant material used corresponds to very old varieties or local denominations. Although the Prospection had been made on a limited area, it had shown the existence of a great varietal diversity in this region. Indeed, 13 "local varieties" were listed in this study and showed high biometric characteristic. The minor varieties detected in the present study should be preserved in germplasm banks in order to prevent their extinction and maintain the biodiversity of the region.

\section{ACKNOWLEDGMENT}

The authors are grateful to all farmers in Oued Laou region for providing necessary facilities for conducting this research work.

\section{REFERENCES}

[1] Zohary, D. and P. Spiegel-Roy (1975). Beginnings of fruit growing in the old world. Science 187:319-327.

[2] Janick, J (2005). The origin of fruits, fruit growing, and fruit breeding. Plant Breed. Rev. 25:255-320.

[3] Khadari, B., C. Grout, S. Santoni, and F. Kjellberg (2005) Contrasted genetic diversity and differentiation among Mediterranean populations of Ficus carica L.: a study using mtDNA RFLP. Genet. Resources Crop Evol. 52:97109.

[4] Zohary, D. and M. Hopf (2000) Domestication of plants in the old world. 3rd ed. University Press, Oxford, England.

[5] Kislev, M.E., A. Hartmann, and O. Bar-Yosef (2006) Early domesticated fig in the Jordan Valley. Science 312:1372-1374.

[6] Mars M (2003). Fig (Ficus carica L.) Genetic resources and breeding. Acta Hort., 605: 19-27.

[7] DPA Hoceima. Direction provinciale de l'agriculture d'Al Hoceima 2018.

[8] Ben Salah M, Lejri MH (1995). Description phénopomologique de quatre variétés de figuier (Ficus carica L.) dans l'oasis de Gafsa. Rev. Régions Arides, 8(1/95): 3-15.

[9] Mars M, Chebli T, Marrakchi M (1998). Multivariate analysis of fig (Ficus carica L.) germplasm in southern Tunisia. Acta Hort., 480: 75-81.

[10] Chatti K, Hannachi-Salhi A, Mars M, Marrakchi M, Trifi M (2004). Analyse de la diversité génétique de cultivars tunisiens de figuier (Ficus carica L.) à l'aide de caractères morphologiques. Fruits, 59: 49-61.

[11] Mars M, Gaaliche B, Ouerfelli I, Chouat S (2009). Systèmes de Production et Ressources Génétiques du figuier (Ficus carica L.) à Djebba et Kesra, deux villages de montagne au nord ouest de la Tunisie. Rev. Régions Arides, 22: 33-45.

[12] Roger, J.P (2000) Identification variétale d'une espèce méconnue: le figuier, Rapp. Interne, Conserv. Bot. Ntl., Porquerolles, France.

[13] Simonet, M., R. Chopinet, and J. Baccialone (1945) Contribution à l' 'etude de quelques variétés de figuiers des Alpes-Maritimes et du Var. Rev. Bot. Appl. 25:44-75. 